\title{
Sperm and Egg Jelly Coat from Sea Urchin Lytechinus variegatus Collected in Rio de Janeiro Contain Distinct Sialic Acid-Rich Polysaccharides
}

\author{
Gabrielle M. Valle ${ }^{1,2}$, Leonardo P. Cinelli ${ }^{3}$, Adriane R. Todeschini ${ }^{4}$, Lycia de Brito- \\ Gitirana $^{5}$, Ana-Cristina E.S. Vilela-Silva ${ }^{1,5}$ and Paulo A.S. Mourão ${ }^{1,2^{*}}$ \\ ${ }^{I}$ Laboratório de Tecido Conjuntivo; Hospital Universitário Clementino Fraga Filho; Universidade Federal do Rio de \\ Janeiro; Rio de Janeiro - RJ - Brasil. ${ }^{2}$ Programa de Glicobiologia; Instituto de Bioquímica Médica; Universidade Federal \\ do Rio de Janeiro; Rio de Janeiro - RJ - Brasil. ${ }^{3}$ Grupo de Glicofármacos; Laboratório Integrado de Prospecção em \\ Produtos Bioativos; Universidade Federal do Rio de Janeiro; Macaé - RJ - Brasil. ${ }^{4}$ Laboratório de Glicobiologia \\ Estrutural e Funcional; Instituto de Biofísica Carlos Chagas Filho; Universidade Federal do Rio de Janeiro; Rio de \\ Janeiro - RJ - Brasil. ${ }^{5}$ Instituto de Ciências Biomédicas; Universidade Federal do Rio de Janeiro; Rio de Janeiro - RJ - \\ Brasil
}

\begin{abstract}
This work found the occurrence of a distinct sialic acid-rich polysaccharide in the sperm surface of the sea urchin Lytechinus variegatus, which differed significantly from a similar molecule found in the egg jelly. The sperm polysaccharide extracted by protease digestion was purified using anion exchange chromatography and characterized using agarose gel electrophoresis, gas chromatography/mass spectrometry and NMR spectroscopy. This polysaccharide was highly sulfated and composed almost exclusively of $N$-acetylneuraminic acid. In contrast, the sialic acid-rich polysaccharide from the egg jelly was composed of $N$-glycolylneuraminic acid and contains several other hexoses in its structure. This new molecule could help to characterize in further detail the mechanism of fertilization in the sea urchin model system. Sulfated polysaccharides from the jelly coat of sea urchins showed species-specificity in inducing the sperm acrosome reaction, providing an example of a signal transduction event regulated by the sulfated polysaccharide. The new sialic acid-rich polysaccharide found in the sperm head could represent a new molecule involved in the biology of the sea urchin fertilization.
\end{abstract}

Key words: sea urchin, sperm, egg jelly coat, fertilization, sialic acid, sulfated polysaccharide

\section{INTRODUCTION}

Fertilization is the result of a series of interactions between the egg and sperm surface molecules (Lennarz et al. 1993). These processes require the presence of species-specific molecules, especially in free spawning marine invertebrates, in order to avoid polyspermy and inter-specific hybridization (Mah et al. 2005). Studies on the structural characterization of polysaccharides from sea urchins led to the discovery of unique polymers (Alves et al. 1997; Vilela-Silva et al. 1999, 2002, 2008). These polysaccharides have simple, linear structures, composed of repeating units of oligosaccharides. The sulfation patterns, glycosidic linkage and repeating monosaccharide units differ among various species of sea urchins. They show species-specificity in inducing the acrosome reaction, providing a clear example of a signal transduction event mediated by the sulfated

*Author for correspondence: pmourao@hucff.ufrj.br 
polysaccharide. This distinct cell-cell recognition mechanism mediated by the sulfated polysaccharide co-exists with the sperm bindin recognition of its egg receptor. The bindin protein exposed by the acrosomal process, reacts with a matching egg membrane receptor (Glabe and Vacquier 1977).

Another important egg jelly molecule is the sialic acid-rich polysaccharide. It potentiates the sperm acrosome reaction induced by the egg's sulfated polysaccharide (Hirohashi and Vacquier 2002). Little information is available concerning the structure of this polysaccharide. It contains polysialic acid chains linked to a core composed of several hexoses. In Hemicentrotus pulcherrimus and Strongylocentrotus purpuratus, this structure terminates with non-reducing end sulfated $N$-glycolylneuraminic acid (Neu5Gc) residues (Kitazume et al. 1994, 1996). Miyata et al. $(2004,2006)$ reported a polysialic acid on the flagella region of the sea urchins $H$. purcherrimus, $S$. purpuratus and $S$. franciscanus. This $8-O$ sulfated Neu5Ac, capped $\quad \alpha-2 \rightarrow 9$-linked polyNeu5Ac-containing molecule, called "flagellasialin", seemed to be related with sperm motility, required for the fertilization. The involvement of flagellasialin in the motility of sea urchin sperm through the intracellular calcium ion regulation has been reported (Kambara et al. 2011). The presence of $\alpha-2 \rightarrow 8$-linked di-, tri-, tetra and polyNeu5Ac unique gangliosides has also been documented in these cells (Ijuin et al. 1996; Miyata et al. 2011). Most sialic acids on the vertebrate cell surface participate in recognition and interaction events during the growth, development and immune response (Nasirikenari et al. 2006; Nacher et al. 2010). Sialic acids are rarely linked to each other to form a polymerized structure (Miyata et al. 2006). Polysialic acids with the degree of polymerization ranging from 8 to 200 sialyl acid residues are found in few animals and some pathogenic bacteria capsules (Sato and Kitajima 2013).

Highly specific interactions assure not only high rates of fertilization but also avoid inter-specific crosses. These aspects are particularly relevant for free spawning marine species, such as sea urchins. Sulfated polysaccharides from the egg jelly coat that induce the sperm acrosome reaction in a specie-specific way, raises an important question: what is the sperm molecule, which interacts with the egg jelly sulfated polysaccharide? An apparent response to this question came when a group of proteins named "receptors for the egg jelly" was described in S. Purpuratus species (Vacquier and Moy 1997). The present work looks for acidic carbohydrate on the surface of sea urchin sperm, which could be regulating the interaction of the egg jelly sulfated polysaccharide with the sperm, through a carbohydrate-carbohydrate interaction, as reported for sponge cell-cell adhesion (Vilanova et al. 2009) and also for some mammalian cell interaction (Hakomori 2004a, 2004b). This work aimed to study the sialic acidrich polysaccharides found in sperm head of sea urchin and to compare this molecule with a similar one found in the female egg jelly.

\section{MATERIAL AND METHODS}

\section{Extraction of Acidic Polysaccharides from the Sea Urchin Gametes}

Mature specimens of the sea urchin $L$. variegatus were collected from the Guanabara Bay (Rio de Janeiro, Brazil) and given intracelomic injection of $0.5 \mathrm{M} \mathrm{KCl}(\sim 2.0 \mathrm{~mL}$ per specimen) to obtain the gametes (Cinelli et al. 2007). Eggs were recognized by an orange color and collected in a solution containing $450 \mathrm{mM} \mathrm{NaCl}, 9.0 \mathrm{mM} \mathrm{KCl}$, $48 \mathrm{mM} \mathrm{MgCl} 2,10 \mathrm{mM} \mathrm{CaCl} 2$, and $6.0 \mathrm{mM}$ $\mathrm{NaHCO}_{3}(\mathrm{pH}$ 8.0). Sperms were recognized by a whitish color and collected in the same solution, except replacing $\mathrm{CaCl}_{2}$ by $20 \mathrm{mM}$ Tris-HCl. The jelly coat was detached from the eggs by $\mathrm{pH}$ shock as previously reported and subjected to centrifugation $(10.000 x \mathrm{~g}$ for $30 \mathrm{~min})$. The supernatant containing the jelly coat was dialyzed against the distilled water, lyophilized and stored at $-20^{\circ} \mathrm{C}$ (Cinelli et al. 2009). The undiluted sperm were immediately centrifuged $(3,000 \times g$ for 15 min). The supernatant, which corresponded to the seminal fluid, was discarded and the pellet containing the sperms was dialyzed against distilled water, lyophilized and stored at $-20^{\circ} \mathrm{C}$ (Cinelli et al. 2009). The crude polysaccharides were extracted from the egg jellies and sperm by papain digestion and purified by ethanol precipitation, as previously described (Albano and Mourão 1986).

\section{Purification of the Acidic Polysaccharides from Sea Urchin Gametes}

The crude polysaccharides from the sperm and egg jelly ( 20 mg of each) were applied to a Mono Q-HPLC column (HR 5/5; Pharmacia Biotech Inc., Uppsala, Sweden) and equilibrated 
with $20 \mathrm{mM}$ Tris- $\mathrm{HCl}(\mathrm{pH}$ 8.0). The column was washed exhaustively with this solution and then eluted with a linear gradient of $\mathrm{NaCl}(0 \rightarrow 2 \mathrm{M})$ in the same buffer. The flow rate of the column was $0.5 \mathrm{~mL} \mathrm{~min}^{-1}$. Fractions of $0.5 \mathrm{~mL}$ were collected and the eluents were analyzed by their metachromasia using 1,9-dimethylmethylene blue (Farndale et al. 1986). The $\mathrm{NaCl}$ concentration was estimated by conductivity. Fractions containing the acidic polysaccharides were pooled, dialyzed against distilled water, and lyophilized.

\section{Agarose Gel Electrophoresis}

Acidic polysaccharides purified from the sea urchin gametes were analyzed by agarose gel electrophoresis as previously described (Dietrich and Dietrich 1976). Briefly, the samples (approximately $15 \mu \mathrm{g}$ ) were applied to a $0.5 \%$ agarose gel and run for $1 \mathrm{~h}$ at $110 \mathrm{~V}$ in $0.05 \mathrm{M}$ 1,3-diaminopropane-acetate ( $\mathrm{pH} 9.0)$. The sulfated polysaccharides in the gel were fixed with $0.1 \%$ $N$-cetyl- $N, N, N$-trimethylammonium bromide solution. After $12 \mathrm{~h}$, the gel was dried and stained with $0.1 \%$ toluidine blue in acetic acid/ethanol/water (0.1:5:5, v/v) (Salgado et al. 2009).

\section{Polyacrylamide Gel Electrophoresis}

The molecular masses of the acidic polysaccharides from the gametes were estimated by polyacrylamide gel electrophoresis. Samples (10 $\mu \mathrm{g}$ of each) were applied to a $6 \%, 1-\mathrm{mm}$-thick polyacrylamide gel slab in $0.02 \mathrm{M}$ Tris- $\mathrm{HCl}(\mathrm{pH}$ 8.6). After electrophoresis ( $100 \mathrm{~V}$ for $30 \mathrm{~min}$ ), the gel was stained with $0.1 \%$ toluidine blue in $1 \%$ acetic acid, then washed in $1 \%$ acetic acid. The molecular mass markers were standard glycosaminoglycans, the same as those used previously (Tovar et al. 1998).

\section{Carbohydrate Content of the Sea Urchin Polysaccharide}

Total hexose was estimated by the method of Dubois et al. (1956) using galactose as standard. For the identification of the type of hexose, the polysaccharide $(\sim 5 \mathrm{mg})$ was hydrolyzed with $6 \mathrm{M}$ trifluoracetic acid at $100^{\circ} \mathrm{C}$ for $5 \mathrm{~h}$, reduced with sodium borohydride and the alditols obtained were acetylated with acetic anhydride: pyridine $(1: 1, \mathrm{v} /$ v) (Kircher 1960). The alditols acetates were dissolved in chloroform and analyzed on GC-MS. The column used was ZB-5ms. The initial temperature of the run was $110^{\circ} \mathrm{C}$ and the final $250^{\circ} \mathrm{C}$ with an increase of $2^{\circ} \mathrm{C} / \mathrm{min}$ (Ahmed et al. 1997).

\section{Identification of the Sialic Acid}

Total sialic acid content was estimated by the Ehrlich assay (Kabat and Mayer 1971), using $N$ glycolylneuraminic acid as standard. Identification of the sialic acid was based on two methods: electrospray ionization tanden mass spectrometry (ESI-MS) or methanolysis followed by the analysis of the trimethylsilylated derivatives on a mass spectrometry/gas liquid chromatography (MS-GC) unit.

For the acidic polysaccharide from the egg jelly, ESI-MS was employed. Sialic acid from the egg jelly polysaccharide and related standards were analyzed by ESI-MS using the Finnigan LCQ ion trap device-Duo (Thermo Electron, San Jose, CA). The samples were introduced into the mass spectrometer under a flow of $5-10 \mu \mathrm{L} \mathrm{min}^{-1}$ with the aid of a micro pump infuser (Harvard Apparatus, Cambridge, MA, USA). The analysis was in positive mode (ESI $\left.{ }^{+}\right)$. The source and the capillary voltage were $4.5 \mathrm{kV}$ and $3 \mathrm{~V}$ (ESI +). The temperature of the capillary was maintained at $200^{\circ} \mathrm{C}$ and the spectra were collected in the range of 200 to $1000 \mathrm{~m} / \mathrm{z}$. The source-induced dissociation (SID) was $25 \mathrm{~V}$. The experimental collision-induced dissociation of the ion captured (ESI-MS/MS or ESI-MSn) was made 20-60\% (1-3 $\mathrm{eV})$ and normalized by the collision energy relative. The spectrum was processed using the $\mathrm{X}$ caliber program (Thermo Electron).

Identification of the sialic acid of the sperm polysaccharide was based on a different methodology. The polysaccharide was methanolized $\left(0.5 \mathrm{M} \mathrm{HCl}\right.$ in methanol at $80^{\circ} \mathrm{C}$ for $18 \mathrm{~h}$ ), neutralized in silver carbonate and re- $N$ acetylated with acetic anhydride. The dried residue was trimethylsilylated by the addition of bis (trimethylsilyl)-trifluoro-acetamide/pyridine $(1: 1, \mathrm{v} / \mathrm{v})$ (Sweeley et al. 1963). The products were analyzed on a MS-GC unit on a DB-1 fused silica column $(30 \mathrm{~m} \times 0.25 \mathrm{~mm}$ i.d.), using helium as the carrier gas. The column temperature was programmed from 120 to $240^{\circ} \mathrm{C}$ at $2^{\circ} \mathrm{C} \mathrm{min}{ }^{-1}$.

\section{NMR Spectroscopy}

NMR spectra were obtained on a Bruker DRX 600 with a $5 \mathrm{~mm}$ triple resonance probe. The samples for NMR spectroscopy were deuterium exchanged by repeated lyophilization from deuterium oxide 
and dissolved in $0.5 \mathrm{~mL}$ of $\mathrm{D}_{2} \mathrm{O}$ before the analysis. Heteronuclear single quantum coherence spectroscopy (HSQC) 2D ${ }^{1} \mathrm{H}_{-}{ }^{13} \mathrm{C}$ spectra with multiplicity editing during selection step was recorded using the Broker program hsqcedtetgp (Willker et al. 1993). ${ }^{1} \mathrm{H}$ protons were referenced to internal trimethylsilyl propionic acid anion at $10 \mathrm{ppm}$ and ${ }^{13} \mathrm{C}$ spectra were referenced to external methanol at $50 \mathrm{ppm}$.

\section{Light Microscopy}

Gonads, eggs and sperms were fixed in $2.5 \%$ glutaraldehyde in filtered seawater and processed according to standard histological techniques for paraffin embedding. Five micrometer serial slices were stained with toluidine blue at $\mathrm{pH} 7.2$ (Kiernan 1990).

\section{Lectin Staining}

The de-paraffinized and hydrated sections were washed in $3 \% \mathrm{H}_{2} \mathrm{O}_{2}$ for $10 \mathrm{~min}$ to block the endogenous peroxidase activity and then washed in phosphate buffer saline (PBS) $0.05 \mathrm{M}$ (pH 7.4). Thereafter, they were incubated in a solution of biotinylated lectins in appropriate dilutions $(1: 4,000)$ at room temperature for $1 \mathrm{~h}$. After three washes in PBS, sections were incubated in a solution containing $0.05 \%$ 3,3 '-diaminobenzidine (DAB) and $0.005 \% \mathrm{H}_{2} \mathrm{O}_{2}$ in $0.05 \mathrm{M}$ PBS (pH 7.4) at room temperature for $1 \mathrm{~min}$ before dehydration and mounting blade. The following biotinylated lectins were used: LCA (Lens culinaris, $\alpha$ mannose), PNA (Arachis hypogaea; $\beta$-galactose) and AAA (Aleuria aurantia, $\alpha$-fucose), which were purchased from Vector (Burlingame CA, USA).

\section{RESULTS}

\section{Sea Urchin Sperm and Egg Jelly Coat Contain Distinct Sialic Acid-Rich Polysaccharides}

Polysaccharides from the egg jelly and sperm of sea urchin were purified on an anionic exchange chromatography. The columns followed using metachromatic assay (Fig.1). The acidic polysaccharides from the egg jelly eluted from the column as two distinct fractions (Fig. 1, Panel A). The one eluted at $\sim 0.8 \mathrm{M} \mathrm{NaCl}$ corresponded to the sialic acid-rich polysaccharide (egg-SP) as demonstrated previously (Alves et al. 1997; Vilela-Silva et al. 1999, 2002). The second acidic polysaccharide fraction from the sea urchin jelly coat eluted at $\sim 1.0 \mathrm{M} \mathrm{NaCl}$ contained a sulfated fucan (SF), with a peculiar structure as characterized previously (Alves et al. 1998; Vilela-Silva et al. 1999, 2002). It was interesting to observe that the sperm also contained a sialic acid-rich polysaccharide (sperm-SP). No sulfated fucan was detected (Fig. 1, Panel B).

The presence of sialic acid on the sperm polysaccharide was confirmed by the positive Ehrlich assay (not shown in the panel). Metachromatic negative fractions corresponding to nucleic acid (NA) that were absent on the extracts from the sea urchins egg jelly were also detected. No hexuronic acid or hexosamine were detected in the sialic acid-rich polysaccharide using carbozole (Bitter and Muir 1962) and ElsonMorgan (Rondle and Morgan 1955) reactions, respectively.

The acidic polysaccharides from the sea urchin gametes differed significantly on their mobility on agarose gel electrophoresis (Fig. 1, Panel C), suggesting they had different structures. They also differed in their molecular masses, as indicated by polyacrylamide gel electrophoresis (Fig. 1, Panel D). Sulfated fucan stayed at the origin of the gel, denoting its high molecular mass. The two sialic acid-rich polysaccharides migrated as a wide dispersed polymer but with significantly lower molecular masses when compared with the sulfated fucan. These acidic polysaccharides from the sea urchin gametes had distinct electrophoretic mobilities when compared with the standard glycosaminoglycans (left lane on the electrophoresis). They also resisted digestion with chondroitin $\mathrm{ABC}$ lyase and to nitrous acid deamination (not shown in the panel).

The chemical analysis showed that the sialic acidrich polysaccharide from the egg jelly coat had a complex sugar composition (Table 1). It contained mannose, glucose, galactose and fucose, besides sialic acid. No significant amount of hexose was found in the sialic acid-rich polysaccharide from the sea urchin sperm, as was also confirmed by GC/MS analysis and NMR spectroscopy (see below).

No signals assigned to amino acids were observed in the NMR spectra, such as signals from the aromatic amino acids at $6.0-7.0 \mathrm{ppm}$. The sulfate content of these polysaccharides was not determined due to small amount of the material. Alternatively, the high sulfate content was estimated by their metachromatic property comparing to that obtained with a standard chondroitin 6-sulfate (Table 1). 

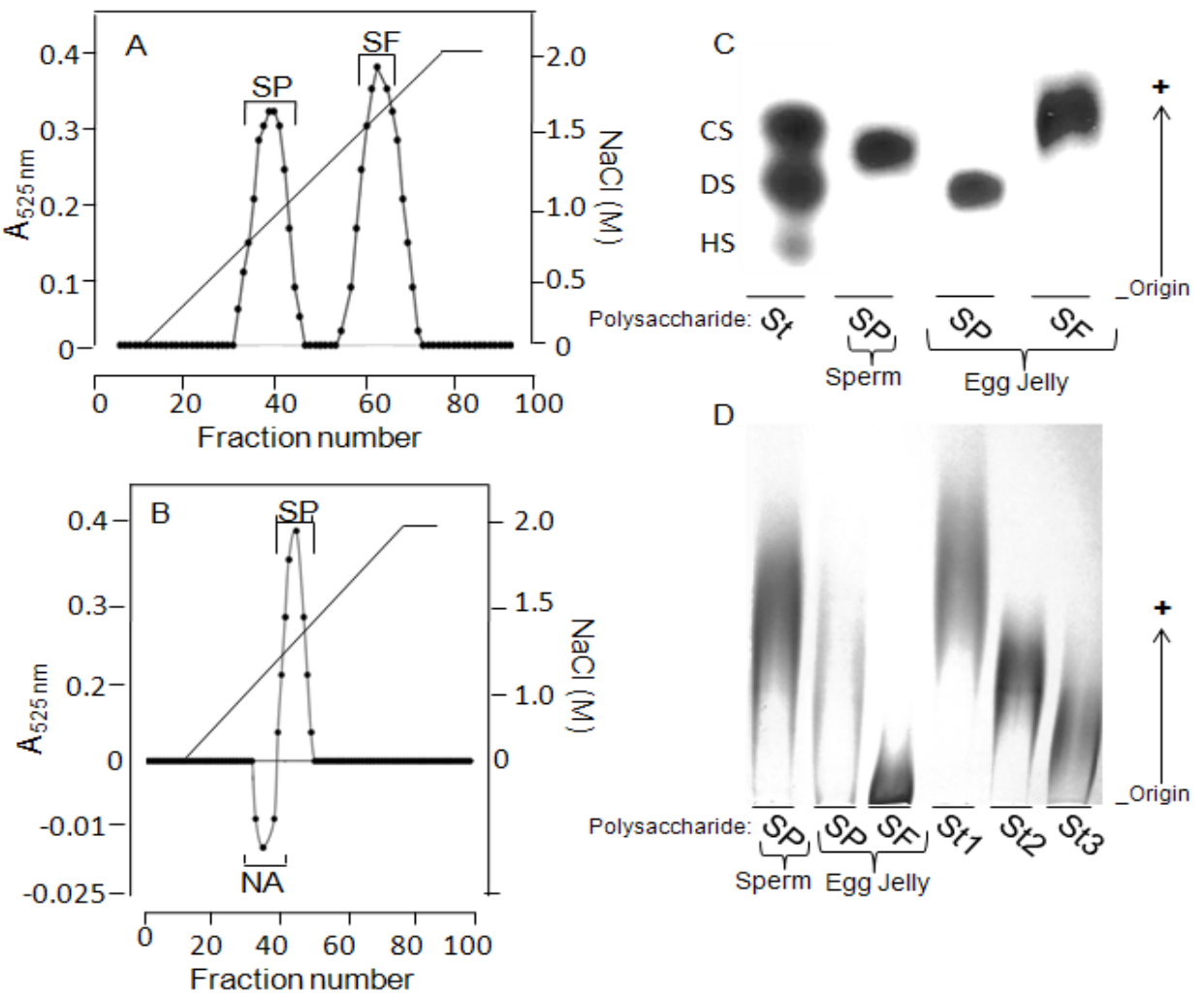

$\mathrm{D}$

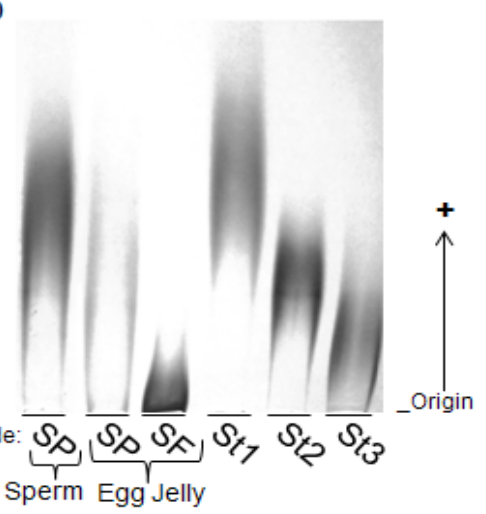

Figure 1 - A, B: Purification of the acidic polysaccharides from the egg jelly (Panel A) and sperm (Panel B) of the sea urchin $L$. variegatus. The crude polysaccharides from egg jellies or from the sperm were applied to a Mono QHPLC column and eluted with a linear gradient of $0 \rightarrow 2 \mathrm{M} \mathrm{NaCl}(---)$. Fractions of $0.5 \mathrm{~mL}$ were collected and analyzed by their metachromasia using 1,9 -dimethylmethylene blue $(\bullet)$. The $\mathrm{NaCl}$ concentration was estimated by conductivity. Fractions containing acidic polysaccharides were pooled, as indicated by the horizontal bars. NA in Panel B indicates nucleic acid, which yield a negative absorbance on the metachromasia assay. C, D: Approximately $15 \mu \mathrm{g}$ of each of the acidic polysaccharides from the sea urchin gametes and a standard mixture of glycosaminoglycans were applied to a $0.5 \%$ agarose gel (Panel C) or to a $6 \%$ polyacrylamide gel (Panel D) for electrophoresis. SF and SP indicate sulfated fucan and sialic acid-rich polysaccharide. CS, DS and HS indicate standards of chondroitin 4-sulfate, dermatan sulfate and heparan sulfate, respectively. The standards of molecular mass used were: low-molecular-weight heparin $(\mathrm{St} 1, \sim 5 \mathrm{kDa})$, unfractionated heparin $(\mathrm{St} 2, \sim 18 \mathrm{kDa})$ and chondroitin 6-sulfate (St3, $60 \mathrm{kDa})$.

Table 1 - Sugar composition of the sulfated polysaccharides from the sea urchin gametes.

\begin{tabular}{|c|c|c|c|c|}
\hline & & & Egg jelly & Sperm \\
\hline & & Sulfated fucan & Sialic acid-rich polysaccharide & Sialic acid-rich polysaccharide \\
\hline Sialic acid & total & $<0.10$ & 0.49 & 1.00 \\
\hline & Neu5Glc & & 0.49 & $<0.10$ \\
\hline & Neu5Ac & & $<0.10$ & 1.00 \\
\hline Hexose & total & 1.00 & 0.51 & $<0.10^{\mathrm{a}}$ \\
\hline & Man & $<0.10$ & 0.17 & \\
\hline & Glc & $<0.10$ & 0.16 & \\
\hline & Gal & $<0.10$ & 0.09 & \\
\hline & Fuc & 1.00 & 0.09 & \\
\hline $\begin{array}{l}\text { Metachrom } \\
\left(\Delta \mathrm{A}_{525 \mathrm{~nm}} \mathrm{p}\right.\end{array}$ & g of sugar) ${ }^{b}$ & 0.410 & 0.327 & 0.342 \\
\hline The GS/MS & $\begin{array}{l}\text { sis (Fig. 2, } \\
\text { rence of siali }\end{array}$ & $\begin{array}{l}\text { Panels A-D) and } \\
\text { acid. }\end{array}$ & R spectroscopy (Fig. 2, Panels & of this polysaccharide confirm th \\
\hline
\end{tabular}


The GS/MS analysis of the trimethylsilylated derivatives from the sperm polysaccharide (Fig. 2, Panels A-D) showed that Neu5Ac was the preponderant sialic acid in the sperm polysaccharide, as indicated by its retention time (Panels A vs. C) and fragmentation pattern (Panels B vs. D), compared with the standard Neu5Ac.

An alternative methodology was used to identify sialic acid found in the egg jelly sialic-rich polysaccharide. Electrospray ionization tandem mass spectrometry (ESI-MS) was employed, since it showed more clear results in the case of this polysaccharide enriched with other types of hexoses. The spectrum of the sea urchin polysaccharide showed that the molecular ion of the sialic acid (Fig. 2, Panels E, F) had the same mass and the same fragmentation as that of standard Neu5Gc (Fig. 2, Panels G, H).
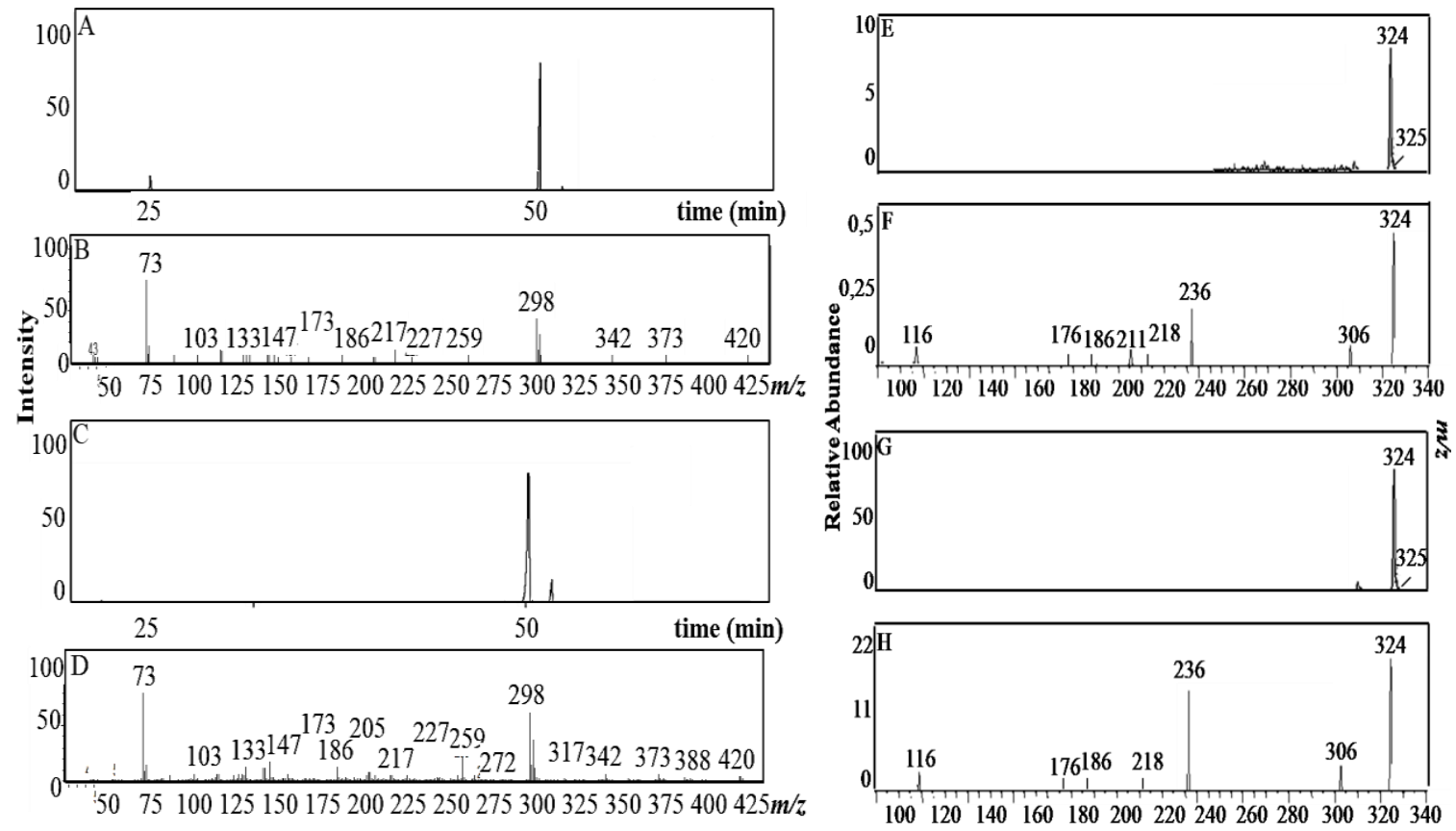

Figure 2 - A-D- Characterization of the sialic acid found in the sperm polysaccharide from sea urchin. Panels A and $\mathrm{C}$ show the elution profile of TMS ether derivatives from the acidic polysaccharide from the sperm and a standard of Neu5Ac, respectively, while Panels B and D show the fragmentation patterns of these two derivatives. E-H: Molecular mass and positive EI-spectrum of GC/MS of sialic acid from the egg jelly polysaccharide. Panels $\mathrm{E}$ and $\mathrm{F}$ show the molecular mass and fragmentation pattern of the sialic acid obtained from egg jelly polysaccharide, respectively. Panels $\mathrm{G}$ and $\mathrm{H}$ show the same result for a standard of Neu5Gc.

The sialic acid glycoconjugate from the egg jelly coat was analyzed using one and two-dimensional $800 \mathrm{MHz}$ NMR spectra, which showed a mixture of poorly resolved signals (not shown here), indicating clearly a complex chemical structure as predicted from its chemical composition (Table 1). In contrast, the ${ }^{1} \mathrm{H}$ NMR spectrum of the sperm polysaccharide showed well-resolved signals. It was not possible to trace clear spin systems in the ${ }^{1} \mathrm{H}-{ }^{1} \mathrm{H}$ TOCSY and COSY spectra. Therefore, it was not possible to assign precisely the NMR signals. However, the edited ${ }^{1} \mathrm{H}-{ }^{13} \mathrm{C}$ HSQC spectrum of the sialic acid-rich polysaccharide from the sperm provided essential information (Fig. 2, Panels I, J). In this experiment, the signals of carbons with odd (red) number of protons were opposite to those with even number (blue) (Willker et al. 1993). This spectrum allowed discriminating glycerol carbons from deoxy carbons at C3 (red) from the other carbons of the pyranose ring (blue). The high number of carbons resonating between 55 and 75 ppm (Fig. 2, Panel J) showed that the polysaccharide contained sialic acids at different chemical environments. The absence of low field signals corroborated the absence of other sugars in this polysaccharide. The presence of high field signal at $23.1 \mathrm{ppm}$, assigned to the acetyl group (Barb et al. 2013), in conjunction with the $\mathrm{C} 3$ signal at $39.5 \mathrm{ppm} \mathrm{C} 3$, correlating with the ${ }^{1} \mathrm{H}$ resonances at 2.87 and 1.98 ppm (Fig. 2, Panel I), characteristic of the H3eq and H3ax signals, confirmed that Neu5Ac was the 
major component of the sperm polysaccharide. Besides, the $50.2 \mathrm{ppm}$ signal, which correlated with a proton at $3.85 \mathrm{ppm}$, was typical of a C5 substituted by an acetamido group at C5. In addition, signal of $\mathrm{C} 4$ could be attributed to the resonance at 71.1 and $3.58 \mathrm{ppm}$. The occurrence of a strongly down-fielded signal at $77.4 \mathrm{ppm}$ corroborated the substitution by a $\left(\mathrm{OSO}_{3}\right)^{\text {-group }}$ (Langeslay et al. 2013) in one of the carbons of the glycerol moiety.

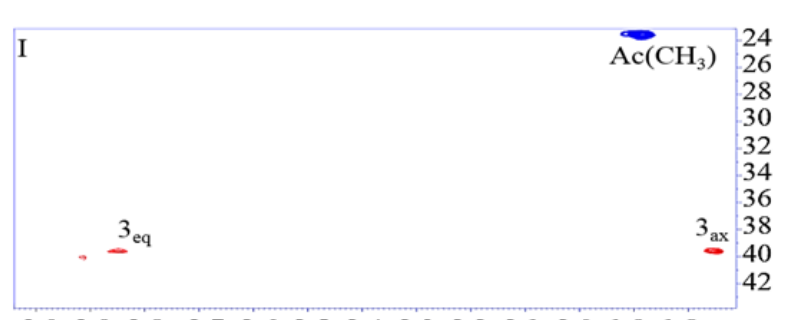

$\begin{array}{lllllllllllll}3.0 & 2.9 & 2.8 & 2.7 & 2.6 & 2.5 & 2.4 & 2.3 & 2.2 & 2.1 & 2.0 & 1.9 & 1.8 \\ \mathbf{p p m}\end{array}$

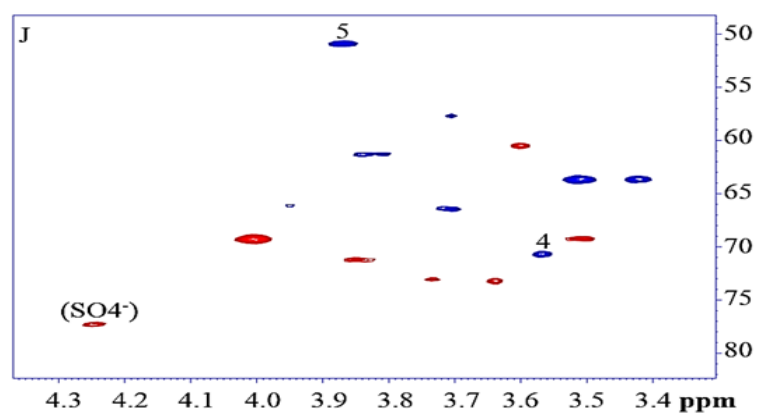

Figure 2 - I, J: $600 \mathrm{MHz} 2 \mathrm{D}{ }^{1} \mathrm{H}-{ }^{13} \mathrm{C}$ edited HSQC spectrum of the acidic polysaccharide from the sperm of sea urchin. Red signals are the carbons with odd number of protons and blue are the carbons with even number of protons. Panel I shows the deoxy carbon $\mathrm{C} 3$ and the $\mathrm{CH}_{3}$ from the acetoamide moiety of Neu5Ac. Panel $\mathrm{J}$ shows the carbons from the glycerol chain (in red) and C4, C5 from Neu5Ac ring (in blue).

Localization of the Acidic Polysaccharides in the Male and Female Gonads of Sea Urchins The male and female gonads of sea urchins were stained with toluidine blue in order to identify the distribution of the acidic polysaccharides (Fig. 3, Panels A-D). The gonads showed intense metachromasia in the eggs and sperm, denoting the presence of the acidic polysaccharides. The female gonad lumen (Fig. 3, Panel B) showed an intense metachromasia around the eggs (that was in their jelly coat), whereas sperm were mostly stained at their head (arrows in Panel C of Fig. 3). The use of biotinylated lectins also allowed to detect the specific sugars on the egg jelly coat (Fig 3, Panels E-G).
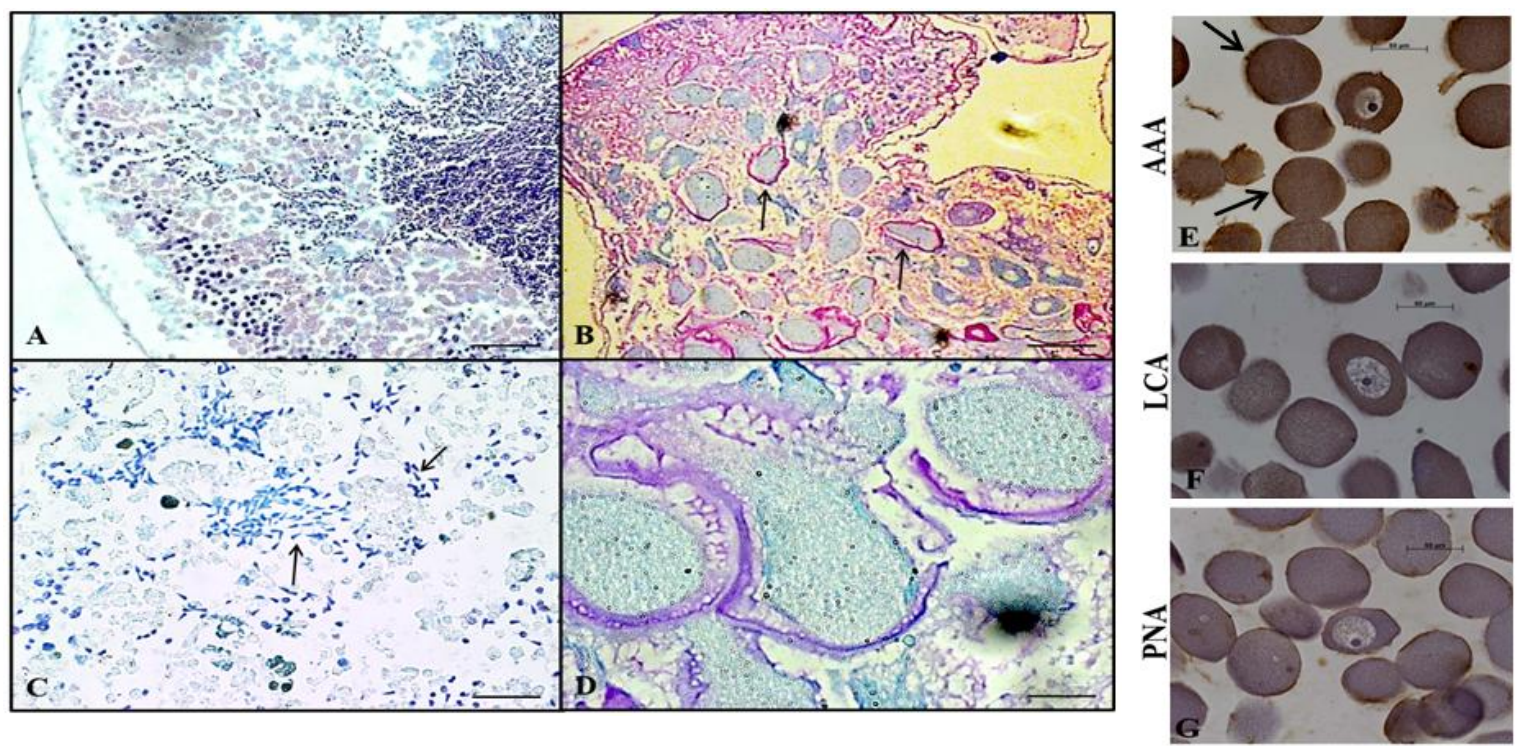

Figure 3 - A-D: Light micrographs of the male (Panel A, x40) and female (Panel B, x40) gonads of the sea urchin and of suspension of the sperm (Panel C, x100) and spawned eggs (Panel D, x100), all stained with toluidine blue. Note the strong metachromasy associated with the sperm (arrows in Panel C) and with the egg jelly coat (arrows in Panel B). The arrows in Panels B and C indicate the egg jelly coat and the head of the sea urchin sperm, respectively. E-G: Light micrographs of the sea urchin eggs stained with biotinylated lectins. The eggs were stained with the following biotinylated lectins: AAA (from Aleuria aurantia, Panel E), LCA (from Lens culinaris, Panel F) and PNA (from Arachis hypogaea, Panel G). Note the staining around the eggs (arrows), denoting their occurrence at the jelly coat. 


\section{DISCUSSION}

The acidic polysaccharides from the sea urchin gametes have structures distinct from the vertebrate glycosaminoglycans, as indicated by their electrophoretic mobility on agarose gel and their resistance to chondroitin $\mathrm{ABC}$ lyase and to nitrous acid deamination. This conclusion was supported by the presence of polysaccharides composed by sulfated fucose units, as reported by previous studies (Vilela-Silva et al. 2002; Cinelli et al. 2007). Sulfated fucans and sialic acid-rich glycoconjugates are the only carbohydrate-rich molecules found around the egg jelly of sea urchins (Mikami-Takey et al. 1991; Vilela-Silva et al. 2008). The sea urchin sperm contains a single fraction of acidic polysaccharide sensitive to metachromasy. Therefore, the positive staining of the sperm in Figure 3, Panels $\mathrm{A}$ and $\mathrm{C}$, was associated exclusively with the sialic acid-rich polysaccharide. In contrast, the egg jelly coat contained two fractions of acidic polysaccharides and the positive metachromasy could be associated with both or either one of them.

Two sialic acid-rich polysaccharides from sea urchin gametes differed significantly in their sugar composition. Hexoses and deoxy hexose (fucose) were found in the sialic acid-rich polysaccharide from the egg jelly coat but they were absent in the sperm molecule. These polysaccharides also differed in their type of sialic acid: $N$ acetylneuraminic acid (Neu5Ac) in the sperm and $\mathrm{N}$-glycolylneuraminic acid (Neu5Gc) in the egg jelly coat polysaccharide. In order to define the exact location of the sialic acid-rich polysaccharide from the egg jelly coat, the additional sugars found in their structure was considered (Table 1). For identify the carbohydrate residues, specific lectins were used: lectins LCA (from Lens culinaris), PNA (from Arachis hypogaea) and AAA (from Aleuria aurantia) that recognized specifically $\alpha$-mannose, $\alpha$-galactose and $\alpha$-fucose, respectively. The biotinylated lectins bound to the sea urchin egg jelly coat (Fig. 3, Panels E-G), denoting the localization of the sialic acid-rich polysaccharide, although this result would need a carefully interpretation because other glycoconjugates might also bind the lectins. However, sulfated fucan and the sialic acid-rich glycoconjugates seemed the only macromolecules rich in carbohydrate found around the egg jelly of sea urchins (Mikami-Takey et al. 1991; VilelaSilva et al. 2008).
Carbohydrates containing sialic acid are present on the surface of vertebrate cells. They participate in the recognition and interaction events that are essential for the growth, development and immunological reaction of these organisms (Nasirikenari et al. 2006; Nacher et al. 2010). Occasionally, sialic acids may be linked to each other to form polymeric structure, as in the capsules of some pathogenic bacteria and in few animal structures (Miyata et al. 2006).

Sialic acid-rich glycoconjugates are found in the zona pellucid of mammalian eggs and also in the jelly coat and vitelline layer overlying sea urchins eggs (Vilela-Silva et al. 2008). The egg jelly coats of the sea urchins, $S$. purpuratus and $H$. pulcherrimus contain polysialic acid composed of sulfated Neu5Gc (Kitazume et al. 1994). The sea urchin $P$. depressus contains a similar polysialic acid structure but is composed of a mixture of $\mathrm{Neu} 5 \mathrm{Gc}$ and $9-\mathrm{O}$-acetyl- $\mathrm{N}$-NeuGc in an equimolar ratio (Kamerling et al. 1980). These sialic acidrich molecules potentiate the acrosome reaction in the sea urchin sperm, which is induced in a species-specific way by the egg jelly sulfated polysaccharides (Hirohashi and Vacquier 2002). Interestingly, one particular species of sea urchin, Glyptocidaris crenularis, sialic acid-rich polysaccharide is absent in the egg jelly (Castro et al. 2009).

Several studies have been conducted on the characterization of sulfated polysaccharides from the egg jelly coat of sea urchins and characterized the unique polysaccharide structures of welldefined units, composed of sulfated fucose or sulfated galactose (Alves et al. 1998; Vilela-Silva et al. 1999 2002). These sulfated polysaccharides induce the sperm acrosome reaction in a speciesspecific way and constitute a barrier for interspecific fertilization in these invertebrates. The proposition of a model system for the involvement of sulfated polysaccharides from the sea urchins egg jelly as a mechanism for regulation the species-specificity in fertilization requires identification of target molecules in the sperm surface. The description of group of proteins named "receptors for the egg jelly" in the sperm of the sea urchin $S$. purpuratus, which bound the egg jelly sulfated fucan (Vacquier and Moy 1997), was a possible way to clarify this issue. However, it was not possible to find similar proteins in the sperm of sea urchin species studied using a similar methodology. Attempts were made to extend the study of sea urchin sperm molecules 
looking for carbohydrate structures, which showed a sialic acid-rich polysaccharide in the sperm. It was highly sulfated but differed from a similar molecule found in the egg jelly due to the occurrence of Neu5Ac instead of Neu5Glc and also due to very low proportion of other constituent sugars (Table 1). The sialic acid-rich polysaccharide from the sperm head had similarity with another glycoconjugate, named flagellasialin, which also contained Neu5Ac (Miyata et al. 2006, 2011).

Studies on whether the sialic acid-rich molecule found in the sperm head interacted with the sulfated fucan from the egg jelly followed the analogy of the interaction of sulfated polysaccharides that regulated sponge cell-cell adhesion (Vilanova et al. 2009). Affinity chromatography was used to investigate possible interaction between the sulfated polysaccharides, as described in the previous publication. The sulfated fucan was linked to a Sepharose matrix and the sperm sialic acid-rich polysaccharide was applied to the affinity column, which was eluted with increasing salt concentration. No interaction was observed when the column was run in the presence or absence of calcium and other bivalent cations. Even in the view of these negative results, it seemed still necessary to investigate the possible role of the new sialic acid-rich polysaccharide from the sea urchin sperm in the biology of fertilization; in particular to pursue alternative methods to investigate carbohydrate-carbohydrate interaction using sea urchin sulfated polysaccharides.

In conclusion, a distinct sialic acid-rich polysaccharide in the sperm of the sea urchin $L$. variegatus was found, which differed significantly from a similar molecule found in the egg jelly. It was not possible to demonstrate the interaction of this sperm polysaccharide with the egg jelly sulfated fucan. However, alternative methods should be studied to investigate possible interactions among these molecules. It could help to characterize the mechanisms of fertilization in the sea urchin model system.

\section{ACKNOWLEDGEMENTS}

This work was supported by the grants from Conselho Nacional de Desenvolvimento Cientifico e Tecnológico (CNPq), Coordenação de
Aperfeiçoamento do Pessoal de Nível Superior (CAPES), and Fundação de Amparo à Pesquisa do Estado do Rio de Janeiro (FAPERJ).

\section{REFERENCES}

Ahmed HJ, Frisk A, Månsson JE, Schweda EK, Lagergård T. Structurally defined epitopes of Haemophilus ducreyi lipooligosaccharides recognized by monoclonal antibodies. Infect Immun. 1997; 65: 3151-3158.

Albano RM, Mourão PA. Isolation, fractionation, and preliminary characterization of a novel class of sulfated glycans from the tunic of Styela plicata (Chordata Tunicata). J Biol Chem. 1986; 261: 758765.

Alves AP, Mulloy B, Diniz JA, Mourão PA. Sulfated polysaccharides from the egg jelly layer are speciesspecific inducers of acrosomal reaction in sperms of sea urchins. J Biol Chem. 1997; 272: 6965-6971.

Barb AW, Wang X, Prestegard JH. Refolded recombinant Siglec5 for NMR investigation of complex carbohydrate binding. Protein Expr Purif. 2013; 88: 183-189.

Bitter T, Muir HM. A modified uronic acid carbazole reaction. Anal Biochem. 1962; 4: 330-334.

Castro MO, Pomin VH, Santos LL, Vilela-Silva AC, Hirohashi N, Pol-Fachin L, et al. A unique 2-sulfated $\beta$-galactan from the egg jelly of the sea urchin Glyptocidaris crenularis: conformation flexibility versus induction of the sperm acrosome reaction. $J$ Biol Chem. 2009; 284: 18790-18800.

Cinelli LP, Castro MO, Santos LL, Garcia CR, VilelaSilva AC, Mourão PA. Expression of two different sulfated fucans by females of Lytechinus variegatus may regulate the seasonal variation in the fertilization of the sea urchin. Glycobiology. 2007; 17: 877-885.

Cinelli LP, Vilela-Silva AC, Mourão PA. Seminal fluid from sea urchin (Lytechinus variegatus) contains complex sulfated polysaccharides linked to protein. Comp Biochem Physiol B Biochem Mol Biol. 2009; 154: 108-112.

Dietrich CP, Dietrich SMC. Electrophoretic behaviour of acidic mucopolysaccharides in diamine buffers. Anal Biochem. 1976; 70: 645-647.

Dubois N, Gilles KA, Hamilton JK, Rebers PA, Smith F. Colorimetric method for determination of sugars and related substances. Anal Chem. 1956; 28: 350356.

Farndale RW, Buttle DJ, Barrett AJ. Improved quantitation and discrimination of sulphated glycosaminoglycans by use of dimethylmethylene blue. Biochim Biophys Acta. 1986; 883: 173-177.

Glabe CG, Vacquier VD. Species specific agglutination of eggs by bindin isolated from sea urchin sperm. Nature. 1977; 267(5614): 836-838. 
Hakomori S. Carbohydrate-to-carbohydrate interaction in basic cell biology: a brief overview. Arch Biochem Biophys. 2004a; 426: 173-181.

Hakomori S. Carbohydrate-to-carbohydrate interaction, through glycosynapse, as a basis of cell recognition and membrane organization. Glycoconj J. 2004b; 21: 125-137.

Hirohashi N, Vacquier VD. Egg sialoglycans increase intracellular $\mathrm{pH}$ and potentiate the acrosome reaction of sea urchin sperm. J Biol Chem. 2002; 277: 80418047.

Ijuin T, Kitajima K, Song Y, Kitazume S, Inoue S, Haslam SM, et al. Isolation and identification of novel sulfated and nonsulfated oligosialyl glycosphingolipids from sea urchin sperm. Glycoconj J. 1996; 13: 401-413.

Kabat EA, Mayer MM. In: Experimental immunochemistry Charles C. Thomas, Springfield, 1971, pp 560-563.

Kambara Y, Shiba K, Yoshida M, Sato C, Kitajima K, Shingyoji C. Mechanism regulating $\mathrm{Ca}^{2+}$-dependent mechano sensory behavior in sea urchin spermatozoa. Cell Struct Funct. 2011; 36: 69-82.

Kamerling JP, Gerwig GJ. Structural analysis of naturally occurring sialic acids. Methods Mol Biol. 2006; 347: 69-91.

Kamerling JP, Schauer R, Vliegenthart JF, Hotta K. Identification of the sialic acids from the egg jelly coat of the sea urchin Pseudocentrotus depressus (Okayama). Hoppe Seylers Z Physiol Chem. 1980; 361: 1511-1516.

Kiernan JA. Histological and histochemical methods. Theory and Practice Pergamon Press Oxford, 1990; $10: 31$.

Kircher JF, Mcnulty JS, Mcfarling JL, Levy A. Irradiation of gaseous and liquid oxygen. Radiat Res. 1960; 13: 452-465.

Kitazume S, Kitajima K, Inoue S, Troy FA, Cho JW, Lennarz WJ, et al. Identification of polysialic acidcontaining glycoprotein the jelly coat of sea urchin eggs. J Biol Chem. 1994; 269: 22712-22718.

Kitazume S, Kitajima K, Inouei S, Haslam SM, Morris HR, Dell A, et al. Occurrence of novel 9-O-sulfated $N$-glycolylneuraminic acid-capped $\alpha 2 \beta 5-O$ glycolyllinked oligo/polyNeu5Gc chains in sea urchin egg cell surface glycoprotein. J Biol Chem. 1996 271: 6694-6701.

Langeslay DJ, Beecher CN, Naggi A, Guerrini M, Torri G, Larive CK. Characterizing the microstructure of heparin and heparan sulfate using Nsulfoglucosamine ${ }^{1} \mathrm{H}$ and ${ }^{15} \mathrm{~N}$ NMR chemical shift analysis. Anal Chem. 2013; 85: 1247-1255.

Lennarz WJ, Ruiz-Bravo N. Identification of molecules involved in sperm-egg fusion. Methods Enzymol. 1993; 221: 261-272.
Mah SA, Swanson WJ, Vacquier VD. Positive selection in the carbohydrate recognition domains of sea urchin sperm receptor for egg jelly (suREJ) Proteins. Mol Biol Evol. 2005; 22: 533-541.

Mikami-Takei K, Kosakai M, Isemura M, Suyemitsu T, Ishihara K, Schmid K. Fractionation of jelly substance of the sea urchin egg and biological activities to induce acrosome reaction and agglutination of spermatozoa. Exp Cell Res. 1991; 192(1): 82-86.

Miyata S, Sato C, Kitamura S, Toriyama M, Kitajima K. A major flagellum sialoglycoprotein in sea urchin sperm contains a novel polysialic acid, an a2,9-linked poly-N-acetylneuraminic acid chain, capped by an 8 O-sulfated sialic acid residue. Glycobiology. 2004; 14: 827-840.

Miyata S, Sato C, Kumita H, Toriyama M, Vacquier VD, Kitajima K. Flagellasialin: a novel sulfated $\alpha$ 2,9-linked polysialic acid glycoprotein of sea urchin sperm flagella. Glycobiology. 2006; 16: 1229-1241.

Miyata S, Yamakawa N, Toriyama M, Sato C, Kitajima $\mathrm{K}$. Co-expression of two distinct polysialic acids, $\alpha 2,8^{-}$and $\alpha 2,9-$ linked polymers of $\mathrm{N}$ acetylneuraminic acid, in distinct glycoproteins and glycolipids in sea urchin sperm. Glycobiology. 2011; 21: 1596-1605.

Nacher J, Guirado R, Varea E, Alonso-Llosa G, Röckle I, Hildebrandt H. Divergent impact of the polysialyltransferases ST8SiaII and ST8SiaIV on polysialic acid expression in immature neurons and interneurons of the adult cerebral cortex. Neuroscience. 2010; 167: 825-837.

Nasirikenari M, Segal BH, Ostberg JR, Urbasic A, Lau JT. Altered granulopoietic profile and exaggerated acute neutrophilic inflammation in mice with targeted deficiency in the sialyltransferase ST6Gal I. Blood. 2006; 108: 3397-3405.

Rondle CJ, Morgan WTJ. The determination of glucosamine and galactosamine. Biochem J. 1955 61: 586-589.

Salgado RM, Favaro RR, Martin SS, Zorn TM. The estrous cycle modulates small leucine-rich proteoglycans expression in mouse uterine tissues. Anat Rec (Hoboken). 2009; 292: 138-153.

Sato C, Kitajima K. Disialic, oligosialic and polysialic acids: distribution, functions and related disease. $J$ Biochem. 2013; 154: 115-136.

Tovar AM, Cesar DC, Leta GC, Mourão PA. Agerelated changes in populations of aortic glycosaminoglycans: species with low affinity for plasma low-density lipoproteins, and not species with high affinity, are preferentially affected. Arterioscler Thromb Vasc Biol. 1998; 18: 604-614. 
Vacquier VD, Moy GW. The fucose sulfate polymer of egg jelly binds to sperm REJ and is the inducer of the sea urchin sperm acrosome reaction. Dev Biol. 1997; 192: 125-135.

Vilanova E, Coutinho CC, Mourão PA. Sulfated polysaccharides from marine sponges (Porifera): an ancestor cell-cell adhesion event based on the carbohydrate-carbohydrate interaction. Glycobiology. 2009; 19: 860-867.

Vilela-Silva AC, Alves AP, Valente AP, Vacquier VD, Mourão PA. Structure of the sulfated alpha-L-fucan from the egg jelly coat of the sea urchin Strongylocentrotus franciscanus: patterns of preferential 2-O- and 4-O-sulfation determine sperm cell recognition. Glycobiology. 1999; 9: 927-933.
Vilela-Silva AC, Castro MO, Valente AP, Biermann $\mathrm{CH}$, Mourão PA. Sulfated fucans from the egg jellies of the closely related sea urchins Strongylocentrotus droebachiensis and Strongylocentrotus pallidus ensure species-specific fertilization. J Biol Chem. 2002; 277: 379-387.

Vilela-Silva AC, Hirohashi N, Mourão PA. The structure of sulfated polysaccharides ensures a carbohydrate-based mechanism for species recognition during sea urchin fertilization. Int J Dev Biol. 2008; 52: 551-559.

Willker W, Leibfritz D, Kerssebaum R, Bermel W. Gradient selection in inverse heteronuclear correlation spectroscopy. Magn Reson Chem. 1993; 31, 287-292. 